\title{
Production of Acyl-Homoserine Lactone Quorum-Sensing Signals by Gram-Negative Plant-Associated Bacteria
}

\author{
Chung Cha, ${ }^{1}$ Ping Gao, ${ }^{1}$ Yu-Ching Chen, ${ }^{1}$ Paul D. Shaw, ${ }^{1}$ and Stephen K. Farrand ${ }^{1,2}$ \\ ${ }^{1}$ Department of Crop Sciences and ${ }^{2}$ Department of Microbiology, University of Illinois at Urbana- \\ Champaign, Urbana 61801, U.S.A. \\ Accepted 16 July 1998.
}

\begin{abstract}
Many gram-negative bacteria regulate expression of specialized gene sets in response to population density. This regulatory mechanism, called autoinduction or quorumsensing, is based on the production by the bacteria of a small, diffusible signal molecule called the autoinducer. In the most well-studied systems the autoinducers are $\mathrm{N}$ acylated derivatives of L-homoserine lactone (acyl-HSL). Signal specificity is conferred by the length, and the nature of the substitution at $\mathrm{C}-3$, of the acyl side-chain. We evaluated four acyl-HSL bioreporters, based on tra of Agrobacterium tumefaciens, lux of Vibrio fischeri, las of Pseudomonas aeruginosa, and pigment production by Chromobacterium violaceum, for their ability to detect sets of 3-oxo acyl-HSLs, 3-hydroxy acyl-HSLs, and alkanoylHSLs with chain lengths ranging from $C_{4}$ to $C_{12}$. The traG::lacZ fusion reporter from the $A$. tumefaciens $\mathrm{Ti}$ plasmid was the single most sensitive and versatile detector of the four. Using this reporter, we screened 106 isolates representing seven genera of bacteria that associate with plants. Most of the Agrobacterium, Rhizobium, and Pantoea isolates and about half of the Erwinia and Pseudomonas isolates gave positive reactions. Only a few isolates of Xanthomonas produced a detectable signal. We characterized the acyl-HSLs produced by a subset of the isolates by thin-layer chromatography. Among the pseudomonads and erwinias, most produced a single dominant activity chromatographing with the properties of $\mathrm{N}$-(3oxo-hexanoyl)-L-HSL. However, a few of the erwinias, and the $P$. fluorescens and Ralstonia solanacearum isolates, produced quite different signals, including 3-hydroxy forms, as well as active compounds that chromatographed with properties unlike any of our standards. The few positive xanthomonads, and almost all of the agrobacteria, produced small amounts of a compound with the chromatographic properties of $\mathrm{N}$-(3-oxo-octanoyl)-L-HSL. Members of the genus Rhizobium showed the greatest diversity, with some producing as few as one and others producing as many as seven detectable signals. Several isolates pro-
\end{abstract}

Corresponding author: Stephen K. Farrand, Department of Crop Sciences, University of Illinois at Urbana-Champaign, 240 ERML, 1201 W. Gregory Dr., Urbana 61801, U.S.A.; Telephone: 1-217-3331524 (office), 1-217-244-3229 (laboratory); Fax: 1-217-244-7830 E-mail: stephenf@uiuc.edu duced extremely nonpolar compounds indicative of very long acyl side-chains. Production of these compounds suggests that quorum-sensing is common as a gene regulatory mechanism among gram-negative plant-associated bacteria.

Quorum-sensing, also called autoinduction, is a mechanism by which bacteria regulate the expression of specialized gene sets in response to their cell density. The bacteria gauge the size of their population by sensing the concentration of small, diffusible, signal molecules called autoinducers that they themselves produce. These molecules pass out of and back into the cells, sometimes by simple diffusion, thereby accumulating in the environment as a function of the growth of the cells. At some threshold concentration, corresponding to a critical population density, these signals serve as co-inducers to regulate transcription of target genes, the products of which presumably are of benefit to the bacteria in the particular habitat.

Autoinduction first was described in the marine symbiotic bacterium Vibrio fischeri (Nealson et al. 1970). This organism, which colonizes the light organs of certain marine fish and cephalopods, regulates expression of genes encoding bioluminescence in response to population density. LuxR, a transcriptional activator, requires a threshold concentration of the $V$. fischeri autoinducer, VAI, in order to activate transcription of the lux operon. In turn, the bacteria produce this autoinducer during their growth in the light organ. According to the current models, once it has reached the necessary concentration, VAI interacts with LuxR, converting the protein into a functional transcriptional activator. LuxR then activates transcription of the lux operon, the first gene of which is luxI. LuxI, the protein coded for by this gene, catalyzes the synthesis of VAI (for reviews see Dunlap and Greenberg 1991; Fuqua et al. 1994; Fuqua et al. 1996). Thus, activation by autoinduction results in the production of increased amounts of the signal and concomitant amplification of the transcription of the target operon. Although regulation of production of the signal is not part of the initial definition of autoinduction it is common among known quorum-sensing systems. But control of signal synthesis by autoinduction is not a de rigueur element of this regulatory paradigm; some organisms express their $I$ genes constitutively (Beck von Bodman and Farrand 1995). 
Over the past few years a number of gram-negative bacteria, representing a range of genera, have been shown to regulate various gene systems by quorum-sensing (see, for example, Throup et al. 1995; Eberl et al. 1996; McClean et al. 1997; Puskas et al. 1997; Swift et al. 1997). Among the better characterized of these, Agrobacterium tumefaciens controls conjugal transfer of several plasmid types by quorum-sensing involving the transcriptional activator TraR and the diffusible signal molecule AAI (Piper et al. 1993; Fuqua and Winans 1994). Pseudomonas aeruginosa regulates several gene systems, including those required for the production of rhamnolipids (Ochsner and Reiser 1995), and extracellular enzymes and toxins (Passador et al. 1993) by two hierarchical quorum-sensing systems, each with its own transcriptional regulator and diffusible signal molecules (Latifi et al. 1996; Pearson et al. 1997). Another pseudomonad, P. aureofaciens $30-84$, regulates production of phenazine antibiotics by quorum-sensing (Pierson et al. 1994). These antibiotics have been implicated in the ability of this bacterium to control take-all disease of wheat in disease-suppressive soils (Thomashow and Weller 1988). Four plant pathogens, Erwinia carotovora (Jones et al. 1993; Pirhonen et al. 1993), E. stewartii (now Pantoea stewartii; Beck von Bodman and Farrand 1995), Ralstonia solanacearum (Clough et al. 1997), and Xanthomonas campestris pv. campestris (Barber et al. 1997), regulate the expression of traits involved in pathogenesis by quorumsensing systems. Significantly, in each case, while the regulatory strategy is similar, the target genes controlled by quorum-sensing are very different.

Most but not all of the autoinducers characterized to date are $\mathrm{N}$-acylated derivatives of L-homoserine lactone (acylHSLs). Such acyl-HSLs produced by various organisms can differ with respect to the length of, nature of the substitution at the 3-carbon position of, and presence or absence of one or more unsaturations within, the acyl side-chain. For example, VAI is $N$-(3-oxo-hexanoyl)-L-HSL (Eberhard et al. 1981), while the Agrobacterium spp. autoinducer, AAI, is $\mathrm{N}$-(3-oxooctanoyl)-L-HSL (Zhang et al. 1993). The active signal molecule produced by Chromobacterium violaceum is $\mathrm{N}$-hexanoylL-HSL (McClean et al. 1997), while the autoinducer synonymous with small bacteriocin produced by some isolates of Rhizobium spp. is $\mathrm{N}$-(3-hydroxy-7-cis-tetradecanoyl)-L-HSL (Gray et al. 1996; Schripsema et al. 1996). Some bacteria produce only a single detectable species of acyl-HSL (McClean et al. 1997) while others, such as $P$. aeruginosa and $R$. etli, can produce as many as seven compounds with detectable activity (Pearson et al. 1994; Winson et al. 1995; Rosemeyer et al. 1998).

Although several bacteria that interact with plants produce compounds with acyl-HSL activity, there has been no systematic survey of this group of organisms for the production of these signal molecules. In this study we assessed the capacity of four reporter systems to detect a variety of acyl-HSL signal molecules differing with respect to the lengths of the sidechain and the nature of the substitution at the 3-carbon position. We used a qualitative, petri dish-based bioassay to screen 106 isolates of plant-associated, gram-negative bacteria representing seven genera for production of compounds with acylHSL signaling activity. We then assessed the complements of acyl-HSLs produced by a subset of these isolates by thin-layer chromatography (TLC).

\section{RESULTS}

Assessing reporter systems.

Acyl-HSL signal molecules are produced and are active at very low concentrations. This precludes the use of most specific and nonspecific chromogenic reagents for detecting these signals in culture supernatants. Moreover, these compounds lack chromophores that strongly absorb light in the visible and UV wavelengths. Thus, these compounds are usually detected by bioassays with, as indicators, constructs in which an exogenously supplied acyl-HSL is required to express an easily detectable trait. We tested four systems for their capacity to detect acyl-HSLs. Three of these, tra, lux, and las, use fusions of the regulated promoter to $l a c Z$ and can be assayed by any of the methods developed for detecting $\beta$-galactosidase activity. The schematic structures of these reporters are shown in Figure 1. The fourth, Chromobacterium violaceum, controls the production of violacein, a violet pigment, by quorumsensing (McClean et al. 1997). Strain CV026blu is a mutant of the wild-type strain that is unable to produce its own acylHSL signal but responds to certain exogenous active signal molecules (McClean et al. 1997).

We assessed the four bioreporters for their ability to detect a range of acyl-HSL standards, and for their sensitivity to these compounds. Following chromatography of three sets of standards at three relative concentrations on four $\mathrm{C}_{18}$ reversedphase TLC plates, each plate was overlaid with a soft agar suspension of one of the four indicator strains as described in

A

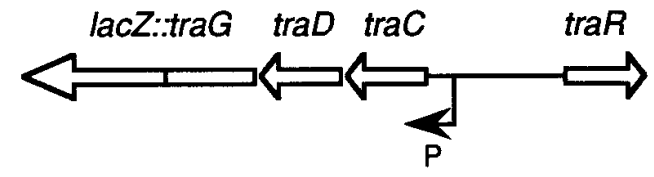

B

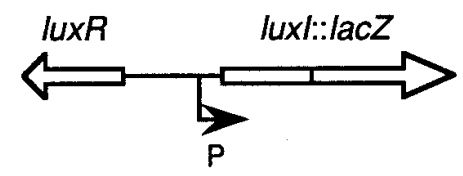

C

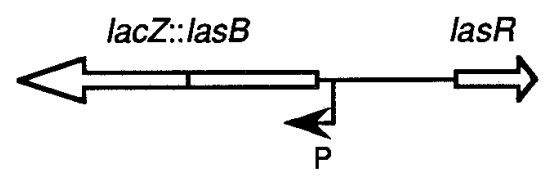

Fig. 1. Structures of $l a c Z$ reporter fusions for the detection of compounds with $N$-acyl-L-homoserine lactone activity. A, traG::lacZ reporter. Plasmid pZLR4 contains the $\operatorname{traCDG}$ operon along with its promoter region from pTiC58. The insert was derived from pTHB58traG::Tn3lac1, which contains a transcriptional fusion of lacZYA from Tn3HoHo1 to traG (Farrand et al. 1996). The clone also contains traR from pTiC58 cloned as a 1.8-kb fragment into the EcoRI site of the vector. B, luxI::lacZ reporter. The insert, cloned in pSUP102, contains $l u x R$, the intergenic luxR-luxI promoter region, and the $5^{\prime}$ portion of luxI fused to lacZ to form pWH141 (Dunlap and Kuo 1992). C, las $B:$ :lac Z reporter. Plasmid pKDT17 contains the las $B$ promoter region and the $5^{\prime}$ portion of lasB fused to lac $Z$ cloned into pUCP18 (Pearson et al. 1994). The plasmid also contains the lasR gene cloned as a separate fragment. Strains harboring these reporter plasmids lack the appropriate $I$ gene and do not produce their own $N$-acyl-L-homoserine lactone signal molecules. However, they will activate transcription of the reporter fusion in response to an exogenous source of active autoinducer. 
Materials and Methods. The A. tumefaciens reporter strain detected the broadest range of acyl-HSL derivatives of all three classes (Fig. 2A). Moreover, this reporter showed the greatest sensitivity, detecting most of the compounds even at one-tenth of the arbitrary standard concentration in the mixes. As we noted previously (Shaw et al. 1997) this strain did not detect $N$-butanoyl-L-HSL, even at 10-fold higher amounts than that present in the standard mix (Figure 2A). The $C$. violaceum reporter, which recognizes $N$-hexanoyl-L-HSL as the cognate signal (McClean et al. 1997), was extremely sensitive to the short- and medium-chain length alkanoyl-HSL standards, and easily detected the $N$-butanoyl-HSL (Fig. 2D,
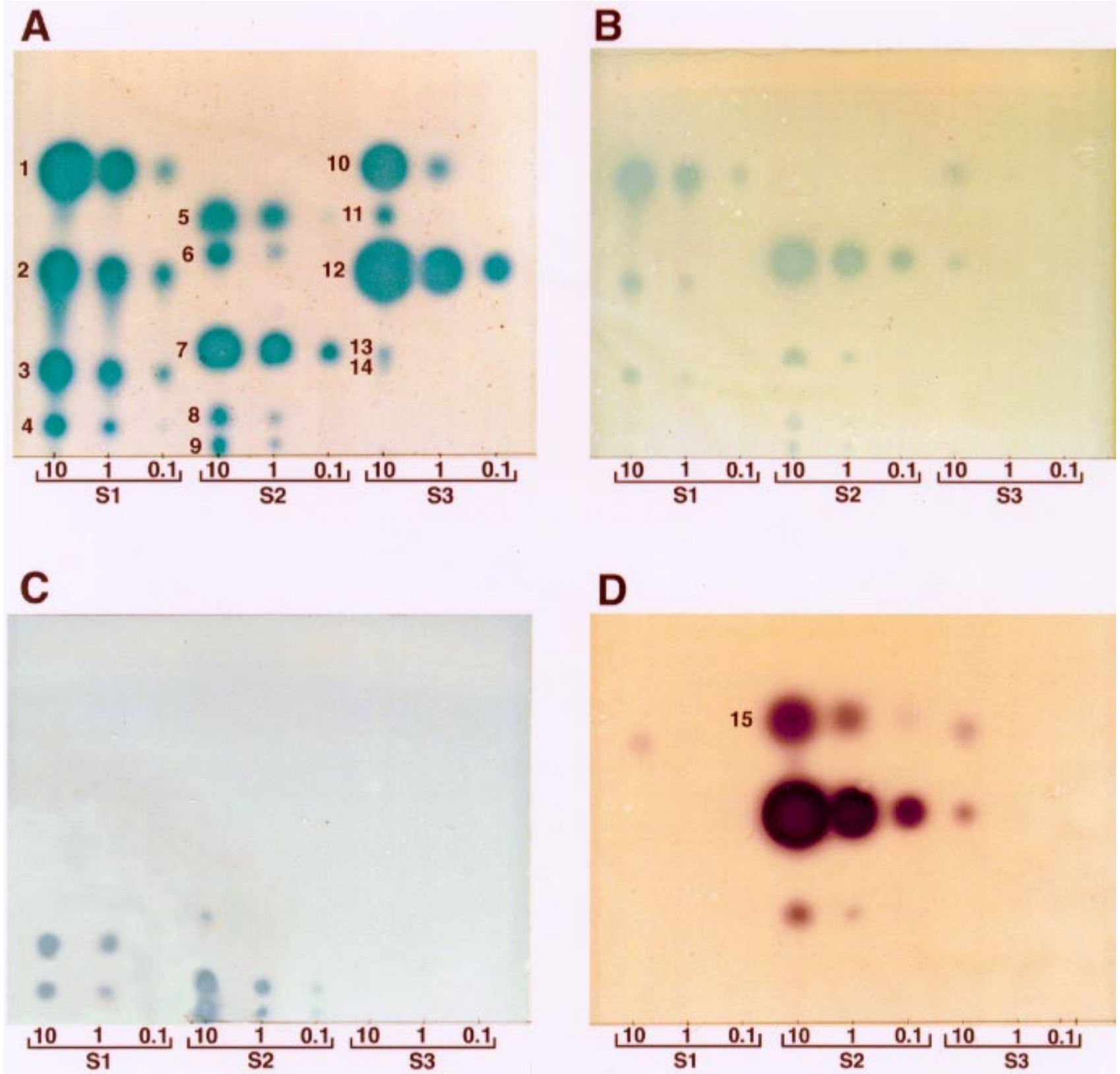

Fig. 2. Specificities and sensitivities of the reporter systems to N-acylated derivatives of L-homoserine lactone (acyl-HSL). Mixtures of the acyl-HSL standards were spotted onto $\mathrm{C}_{18}$ reversed phase thin-layer plates and chromatographed with methanol/water (60:40, vol/vol). Following development, the plates were air dried and overlaid with suspensions of the indicator strains: A, Agrobacterium tumefaciens NT1(pZLR4); B, Escherichia coli XL1Blue(pWH141); C, E. coli MG4(pKDT17); and D, Chromobacterium violaceum CV026blu, all as described in Materials and Methods. Standard mixes are as follows: $S 1,3$-oxo derivatives with acyl chain lengths of (1) $\mathrm{C}_{6}$, (2) $\mathrm{C}_{8}$, (3) $\mathrm{C}_{10}$, (4) $\mathrm{C}_{12}$; $\mathrm{S} 2$, alkanoyl derivatives with acyl chain lengths of (5) unknown contaminant, (15) $C_{4}$, (6) $C_{6}$, (7) $C_{8},(8) C_{10}$, (9) $C_{12}$; S3, 3-hydroxy derivatives with acyl chain lengths of (10) $C_{6}$, (11) unknown component, (12) $\mathrm{C}_{8}$, (13) $N$-octanoyl-HSL, (14) $\mathrm{C}_{10}$. S3 sample was prepared as an ethyl acetate extract of culture supernatants of Pseudomonas fluorescens 279 as described in Materials and Methods. Each set of standards was applied to the plate at three relative concentrations. $1=\mathrm{a}$ set of concentrations of each species that gives easily and reproducibly detectable spots with the traG::lacZ reporter as previously described (Shaw et al. 1997). 0.1 and $10=$ one-tenth and 10-times the loading amounts of the standards present in concentration sets 1, respectively. In all cases, samples were loaded in a total volume of $1 \mu \mathrm{l}$. 
spot 15). However, as previously reported (McClean et al. 1997), this strain lacks sensitivity to alkanoyl-HSLs with longer chain lengths and to most of the 3-oxo- derivatives. The strain also did not detect any of the 3-hydroxy- derivatives; the two spots in the $\times 10 \mathrm{~S} 3$ lane of Figure 2D correspond to the $N$-hexanoyl-L-HSL and $N$-octanoyl-L-HSL species present in the extract from $P$. fluorescens we use as our source of 3-hydroxy acyl-HSL standards (data not shown). The lux reporter detected most of the 3-oxo- and alkanoylstandards but did not detect $N$-butanoyl-L-HSL or any of the 3-hydroxy forms at the concentrations tested (Fig. 2B). Like the $C$. violaceum reporter, the lux indicator detected the $\mathrm{N}$ hexanoyl-L-HSL and $N$-octanoyl-L-HSL species present in the 3-hydroxy standard mix (Figure 2B, $\times 10$ S3 lane). Moreover, the lux reporter responded with less intensity and was considerably less sensitive to the compounds, compared with the tra reporter. The las reporter responded strongly to $N$-decanoyl-LHSL and $N$-dodecanoyl-L-HSL and less strongly to the $N$-(3oxo-decanoyl)-L-HSL and $\mathrm{N}$-(3-oxo-dodecanoyl)-L-HSL standards, and did not detect any of the 3-hydroxy compounds at the concentrations tested (Fig. 2C). Nor did the las reporter detect any of the shorter chain, $\mathrm{C}_{4}, \mathrm{C}_{6}$, and $\mathrm{C}_{8}$ signals at the standard concentrations, although it weakly detected $\mathrm{N}$ octanoyl-L-HSL at the $\times 10$ concentration (Fig. 2D, lane 4). We should note that our alkanoyl- standard mix contains a contaminant detectable by the tra reporter as the fastest migrating activity (Shaw et al. 1997; see Figure 2A, spot 5). We do not know the nature of this compound, but it is not detected by any of the other reporters. Interestingly, this compound comigrates with an unknown active species present in the 3hydroxy standard mix prepared from a culture of $P$. fluorescens 2-79 (Fig. 2A, spot 11). This unknown signal also is not detected by any of the other reporters.

Given the range and sensitivity of detection shown by the $A$. tumefaciens tra reporter we used this system for all of our assays unless otherwise noted.

\section{Surveying plant-associated bacteria.}

Using our petri dish assay, we surveyed 106 isolates representing seven genera of plant-associated, gram-negative bacteria-Agrobacterium, Erwinia, Pantoea, Pseudomonas, Ralstonia, Rhizobium, and Xanthomonas-for the production of compounds with acyl-HSL activity. The tested strains represent pathogens and a few nonpathogenic and race mutants, commensals, and symbionts. The results, along with the source of the organism and the medium used for the tests, are presented in Table 1.

With the exception of the xanthomonads, production of compounds giving a positive signal was common among isolates from all genera tested. However, within each genus, production of these activities often was species dependent. For example, all three isolates of E. carotovora tested produced an easily detectable activity, but none of the three E. amylovora isolates tested gave a positive reaction. Moreover, among the isolates of E. chrysanthemi and E. herbicola tested, some gave a positive response while others failed to produce a detectable activity. Similar diversity was seen within and among biovars of Pseudomonas syringae. With the exception of the two phenazine producers, $P$. aureofaciens 30-84 and $P$. fluorescens 2-79, other pseudomonads, including $P$. putida and $P$. fluorescens, generally failed to give a positive reaction.
Most of the Agrobacterium spp. isolates produced a very weak reaction from the indicator. The remainder, including one strain of $A$. rhizogenes, one strain of $A$. tumefaciens, and two of the $A$. vitis isolates, failed to give a positive reaction. Similarly, all but one of the rhizobial isolates gave a distinctly positive reaction.

The xanthomonads proved particularly difficult to assess. Several isolates, including X. campestris pv. campestris 4546 , $X$. campestris pv. pelargoni X-5, and X. oryzae pv. oryzicola BLS303, clearly produced an active species (see below). Other isolates often induced in the indicator overlay a very narrow zone of diffusing blue color around the colony. However, these reactions were not reproducible. Moreover, such isolates occasionally gave a comparable ring of activity even when the indicator strain was omitted from the overlay. These isolates evidently produce some extracellular factor that hydrolyzes X-Gal. Given this, we retested each positive isolate on a plate lacking the indicator strain to rule out such falsepositive reactions. No other isolates gave such a reaction.

\section{Assessing acyl-HSL complements by TLC.}

TLC, coupled with a bioreporter, provides a simple and rapid technique for assessing the minimum number of different acyl-HSL species produced by a given organism (Shaw et al. 1997). The technique also provides limited and preliminary information concerning the nature of these compounds present in extracts of the culture supernatants. However, one cannot assign structures to the active signals based on chromatographic properties alone.

We analyzed by TLC extracts from culture supernatants of selected isolates, representing each of the genera listed in Table 1 , that had given positive reactions in the petri dish assay. In each case we detected the separated acyl-HSLs with two indicators: the traG::lacZ reporter from A. tumefaciens, and, to detect the short-chain alkanoyl-HSLs, the $C$. violaceum reporter (see above). The results, illustrated in Figure 3 for a representative group of the strains tested, can be summarized as follows. The isolates of the Pseudomonas syringae group tested all produced as the dominant activity a compound that is chromatographically indistinguishable from the $\mathrm{N}$-(3-oxohexanoyl)-L-HSL standard (Fig. 3A, lanes 1-3). Many of these isolates also produced at barely detectable levels a compound that co-chromatographed with $\mathrm{N}$-(3-oxo-octanoyl)-LHSL. The $C$. violaceum indicator detected a weakly reactive component that could be $N$-hexanoyl-L-HSL in extracts prepared from culture supernatants of each of the three $P$. syringae strains (data not shown). Similarly, most of the Erwinia isolates we examined produced an active compound that cochromatographed with $N$-(3-oxo-hexanoyl)-L-HSL as the dominant signal molecule (Fig. 3B, lanes 2 and 3). However, there were a few exceptions. Erwinia carotovora subsp. atroseptica produced at least four detectable species (Fig. 3B, lane $2)$. Two of these chromatographed with the characteristics of $N$-(3-oxo-hexanoyl)-L-HSL and $N$-(3-oxo-octanoyl)-L-HSL. The remaining activities chromatographed with characteristics unlike any of our standards. One of these has properties similar to the unknown contaminant in the alkanoyl-HSL standards mix while the second is more polar than even our $\mathrm{C}_{4}$ standards.

Strain 2-79, the single isolate of $P$. fluorescens that gave a positive reaction in the plate assay, produced five species detectable with the tra reporter. These correspond to $\mathrm{N}$-(3- 
Table 1. Strains, their characteristics and sources, and their production of compounds with $N$-acyl-L-homoserine lactone activity

\begin{tabular}{|c|c|c|c|c|c|c|c|c|c|}
\hline $\begin{array}{l}\text { Genus, species, biovar or } \\
\text { pathovar }\end{array}$ & Strain & Source & Medium $^{b}$ & $\mathbf{R}^{\mathbf{c}}$ & $\begin{array}{l}\text { Genus, species, biovar or } \\
\text { pathovar }\end{array}$ & Strain & Source & Medium $^{b}$ & $\mathbf{R}^{\mathbf{c}}$ \\
\hline \multirow[t]{3}{*}{ Erwinia amylovora } & 273 & S. M. Ries & $\mathrm{ABM} / \mathrm{LB}$ & - & X. campestris pv. campestris & NA5 & J. E. Leach & LB & - \\
\hline & FB01 & D. L. Coplin & $\mathrm{ABM} / \mathrm{LB}$ & $-^{\mathrm{d}}$ & & 477 & J. E. Leach & LB & + \\
\hline & FB03 & D. L. Coplin & $\mathrm{ABM} / \mathrm{LB}$ & $-^{\mathrm{d}}$ & & 4546 & J. E. Leach & LB & + \\
\hline E. carotovora bv. atroseptica & SR8 & D. L. Coplin & ABM & +++ & & 4547 & J. E. Leach & LB & $-^{\mathrm{d}}$ \\
\hline \multirow[t]{2}{*}{ E. carotovora bv. carotovora } & SR29 & D. L. Coplin & $\mathrm{ABM}$ & +++ & X. campestris pv. cerealis & NCPPB1943 & J. E. Leach & LB & $-{ }^{\mathrm{d}}$ \\
\hline & DM2105 & D. L. Coplin & $\mathrm{ABM}$ & +++ & X. campestris pv. glycines & FI & I. Hwang & LB & + \\
\hline \multirow[t]{7}{*}{ E. chrysanthemi } & FI & S. M. Ries & $\mathrm{ABM}$ & - & & 426 & J. E. Leach & LB & $-^{\mathrm{d}}$ \\
\hline & 873 & A. Collmer & $\mathrm{ABM}$ & +++ & & 479 & J. E. Leach & LB & - \\
\hline & D759 & A. Collmer & ABM & +++ & X. campestris pv. holicola & 86 & J. E. Leach & LB & $-^{\mathrm{d}}$ \\
\hline & 16 & A. Collmer & $\mathrm{ABM}$ & +++ & & 429 & J. E. Leach & LB & - \\
\hline & SR120A & A. Collmer & $\mathrm{ABM} / \mathrm{LB}$ & $-{ }^{\mathrm{d}}$ & $\begin{array}{l}X . \text { campestris pv. malva- } \\
\text { cearum }\end{array}$ & $\mathrm{R}-2$ & J. E. Leach & LB & $-{ }^{\mathrm{d}}$ \\
\hline & 3937 & A. Collmer & $\mathrm{ABM} / \mathrm{LB}$ & - & X. campestris pv. pelargoni & $\mathrm{X}-1$ & J. E. Leach & LB & $\mathrm{e}^{\mathrm{e}}$ \\
\hline & D706 & A. Collmer & $\mathrm{ABM} / \mathrm{LB}$ & - & & $X-5$ & J. E. Leach & LB & + \\
\hline \multirow[t]{3}{*}{ E. herbicola } & FI & S. M. Ries & $\mathrm{ABM} / \mathrm{LB}$ & - & X. campestris pv. vesicatoria & FI & I. Hwang & LB & - \\
\hline & DC531 & D. L. Coplin & ABM & +++ & & $82-8$ & B. Staskawicz & LB & $-^{\mathrm{d}}$ \\
\hline & DC535 & D. L. Coplin & $\mathrm{ABM} / \mathrm{LB}$ & $-^{\mathrm{d}}$ & & 82-8avrBS2 & B. Staskawicz & LB & - \\
\hline \multirow{2}{*}{ E. rhapontici } & DC541 & D. L. Coplin & $\mathrm{ABM} / \mathrm{LB}$ & $-^{\mathrm{d}}$ & X. oryzae pv. oryzae & PX061 & J. E. Leach & LB & $-^{\mathrm{d}}$ \\
\hline & DC542 & D. L. Coplin & $\mathrm{ABM} / \mathrm{LB}$ & - & & PX099 & J. E. Leach & LB & - \\
\hline \multirow{4}{*}{ Pantoea stewartii } & FI & S. M. Ries & ABM & +++ & $X$. orvzae pv. orvzicola & BLS179 & J. E. Leach & LB & + \\
\hline & ESR5 & D. L. Coplin & $\mathrm{ABM}$ & +++ & & BLS303 & J. E. Leach & LB & + \\
\hline & SS104 & D. L. Coplin & $\mathrm{ABM}$ & +++ & Agrobacterium radiobacter & K84 & OC & $\mathrm{ABMB}$ & + \\
\hline & SW2 & D. L. Coplin & $\mathrm{ABM}$ & +++ & & K299 & $\mathrm{OC}$ & $\mathrm{ABMB}$ & + \\
\hline Pseudomonas aureofaciens & $30-84$ & L. Thomashow & VB & + & A. rhizogenes & $\mathrm{A} 4$ & $\mathrm{OC}$ & $\mathrm{ABMB}$ & + \\
\hline \multirow{2}{*}{ P. fluorescens } & $2-79$ & L. Thomashow & $\mathrm{VB} / \mathrm{ABM}$ & +++ & & 8196 & $\mathrm{OC}$ & $\mathrm{ABM}$ & $-\mathrm{d}$ \\
\hline & 1855.344 & OC & $\mathrm{VB} / \mathrm{KB}$ & $-\mathrm{d}$ & & K599 & $\mathrm{OC}$ & $\mathrm{ABM}$ & + \\
\hline \multirow[t]{2}{*}{ P. putida } & B53 & $\mathrm{OC}$ & $\mathrm{VB} / \mathrm{KB}$ & $-^{\mathrm{d}}$ & A. tumefaciens & C58 & $\mathrm{OC}$ & $\mathrm{ABM}$ & + \\
\hline & PRS2000 & $\mathrm{OC}$ & $\mathrm{VB} / \mathrm{KB}$ & - & & $\mathrm{C} 58 \Delta \mathrm{accR}$ & $\mathrm{OC}$ & $\mathrm{ABM}$ & +++ \\
\hline P. syringae pv. angulata & PA1 & $\mathrm{OC}$ & VB & +++ & & A6 & $\mathrm{OC}$ & $\mathrm{ABM}$ & + \\
\hline$P$. syringae pv. coronofaciens & $\mathrm{PC} 27$ & OC & VB & +++ & & B6 & $\mathrm{OC}$ & $\mathrm{ABM}$ & + \\
\hline$P$. syringae $\mathrm{pv}$ glycinea & PG79 & OC & VB & +++ & & 15955 & $\mathrm{OC}$ & $\mathrm{ABM}$ & + \\
\hline P. syringae pv. maculicola & 4326 & D. N. Nunn & $\mathrm{VB} / \mathrm{KB}$ & - & & $15955 \operatorname{tra}^{\mathrm{c}}$ & $\mathrm{OC}$ & $\mathrm{ABM}$ & +++ \\
\hline$P$. syringae pv. melea & PM1020 & D. N. Nunn & $\mathrm{VB} / \mathrm{KB}$ & - & & Bo542 & $\mathrm{OC}$ & $\mathrm{ABM}$ & + \\
\hline P. syringae pv. phaseolicola & 3121 & N. Panopoulos & $\mathrm{VB} / \mathrm{KB}$ & $-^{\mathrm{d}}$ & & Chry 5 & S. Pueppke & $\mathrm{ABM}$ & + \\
\hline \multirow{2}{*}{$\begin{array}{l}\text { P. syringae pv. savastanoi } \\
\text { (olive) }\end{array}$} & 1020 & Y. Dessaux & VB & ++ & & Ant4 & Y. Dessaux & $\mathrm{ABM}$ & + \\
\hline & 1670 & Y. Dessaux & VB & ++ & & $\mathrm{AB} 2 / 73$ & OC & $\mathrm{ABMB}$ & + \\
\hline \multirow{2}{*}{$\begin{array}{l}\text { P. syringae pv. savastanoi } \\
\text { (oleander) }\end{array}$} & 2088 & Y. Dessaux & $\mathrm{VB} / \mathrm{KB}$ & - & & K108 & A. Kerr & $\mathrm{ABM}$ & ${ }_{-d}^{d}$ \\
\hline & T12-1 & Y. Dessaux & VB & ++ & A. vitis & K308 & L. W. Moore & $\mathrm{ABM}$ & - \\
\hline \multirow{3}{*}{$\begin{array}{l}\text { P. syringae pv. savastanoi } \\
\text { (ash) }\end{array}$} & 2093 & Y. Dessaux & $\mathrm{VB} / \mathrm{KB}$ & - & & $\mathrm{Hm} 1$ & L. Otten & $\mathrm{ABM}$ & ${ }^{\mathrm{d}}$ \\
\hline & 2169 & Y. Dessaux & VB & ++ & & Ag57 & E. W. Nester & ABM & + \\
\hline & 2174 & Y. Dessaux & $\mathrm{VB} / \mathrm{KB}$ & - & Rhizobium etli & CFN42 & S. Brom & YEM & +++ \\
\hline \multirow[t]{3}{*}{ P. syringae pv. syringae } & FI & S. M. Ries & $\mathrm{VB} / \mathrm{KB}$ & - & & G12 & T. Reitz & YEM & ++ \\
\hline & Cit7 & S. E. Lindow & $\mathrm{VB} / \mathrm{KB}$ & $-^{\mathrm{d}}$ & R. fredii & USDA191 & G. Elkan & YEM & + \\
\hline & B728a & D. K. Willis & VB & +++ & $\begin{array}{l}\text { R. leguminosarum bv. } \\
\text { phaseoli }\end{array}$ & $127 \mathrm{~K} 14$ & W. Lepps & YEM & ++ \\
\hline \multirow[t]{4}{*}{ P. syringae pv. tabaci } & BR2.004 & $\mathrm{OC}$ & VB & +++ & & 14482 & E. P. Greenberg & YEM & ++ \\
\hline & BR2.024 & $\mathrm{OC}$ & VB & +++ & R. leguminosarum bv. trifolii & $162 \mathrm{E} 8$ & W. Lepps & YEM & ++ \\
\hline & 81 & $\mathrm{OC}$ & VB & +++ & & 14480 & E. P. Greenberg & YEM & ++ \\
\hline & 11528 & OC & VB & +++ & R. leguminosarum bv. viciae & $128 \mathrm{C} 53$ & W. Lepps & YEM & $-{ }^{\mathrm{d}}$ \\
\hline \multirow[t]{2}{*}{ P. syringae pv. tomato } & DC3000 & D. K. Willis & $\mathrm{VB} / \mathrm{KB}$ & - & & $175 \mathrm{~F} 3$ & W. Lepps & YEM & ++ \\
\hline & 2212 & $\mathrm{OC}$ & $\mathrm{VB} / \mathrm{KB}$ & _- & & 10004 & K. Gray & YEM & ++ \\
\hline \multirow[t]{3}{*}{ Ralstonia solanacearurm } & AW1 & T. P. Denny & $\mathrm{CPG} / \mathrm{VB}$ & +++ & R. meliloti & $\mathrm{Rm} 41$ & A. Kondorosi & YEM & +++ \\
\hline & $\mathrm{B} 1$ & L. Sequeira & $\mathrm{CPG} / \mathrm{VB}$ & +++ & & $\mathrm{AK} 631^{\mathrm{e}}$ & A. Kondorosi & YEM & +++ \\
\hline & $\mathrm{K} 60^{\mathrm{e}}$ & L. Sequeira & CPG/VB & +++ & & $\mathrm{Rm} 1021$ & K. Gray & YEM & + \\
\hline $\begin{array}{l}\text { Xanthomonas campestris pv. } \\
\text { campestris }\end{array}$ & FI & I. Hwang & LB & - & & L5-30 & S. Long & YEM & ++ \\
\hline
\end{tabular}

a Abbreviations: OC, our collection; ABM, AB minimal mannitol medium; ABMB, ABM supplemented with biotin; KB, King's medium B; LB, LuriaBertani medium (low salt); VB, Vogel-Bonner medium; YEM, yeast extract mannitol medium; FI, field isolate.

${ }^{\mathrm{b}}$ When two media are shown, the strain was tested in both.

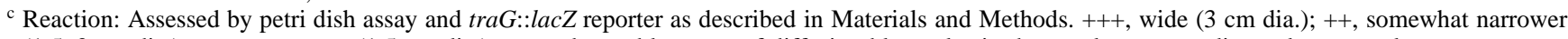
(1.5-3 cm dia.); +, very narrow (1.5 cm dia.); -, no detectable zones of diffusing blue color in the overlay surrounding colony or culture supernatant being tested. In most cases the colony or spot was approximately 0.5 to $1 \mathrm{~cm}$ in diameter.

${ }^{\mathrm{d}}$ Strains giving a negative response on petri dish assay that were tested by thin-layer chromatography. No compounds with $N$-acyl-L-homoserine lactone activity were detected in extracts of culture supernatants from any of these strains.

${ }^{\mathrm{e}}$ Strain K60 is a spontaneous, nonpathogenic mutant of $R$. solanacearum B1; AK631 is a spontaneous compact-colony morphology mutant of $R$. meliloti Rm41 (Forrai et al. 1983). 
hydroxy-hexanoyl)-L-HSL,$\quad N$-(3-hydroxy-octanoyl)-L-HSL, $N$-(3-hydroxy-decanoyl)-L-HSL, and $N$-octanoyl-L-HSL we previously identified in extracts of culture supernatants from this bacterium (Shaw et al. 1997). The C. violaceum reporter detected an additional weak activity corresponding to $\mathrm{N}$ hexanoyl-L-HSL in extracts of this strain (data not shown). We also examined three strains of Ralstonia solanacearum, the two pathogenic isolates, AW1 and B1, and the spontaneous nonpathogenic mutant of $\mathrm{B} 1$, strain K60. As we previously reported, strain B1 produces two species detectable with the

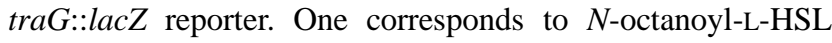
and the second chromatographed with the characteristics of $N$ (3-hydroxy-octanoyl)-L-HSL (data not shown). The independent pathogenic isolate AW1 produced an identical pattern (Fig. 3A, lane 5). Strain K60, the nonpathogenic variant of $\mathrm{B} 1$, produced the same two active species at indistinguishable levels (Fig. 3A, lane 6). The C. violaceum reporter detected only a single active component co-migrating with $\mathrm{N}$-octanoyl-
A

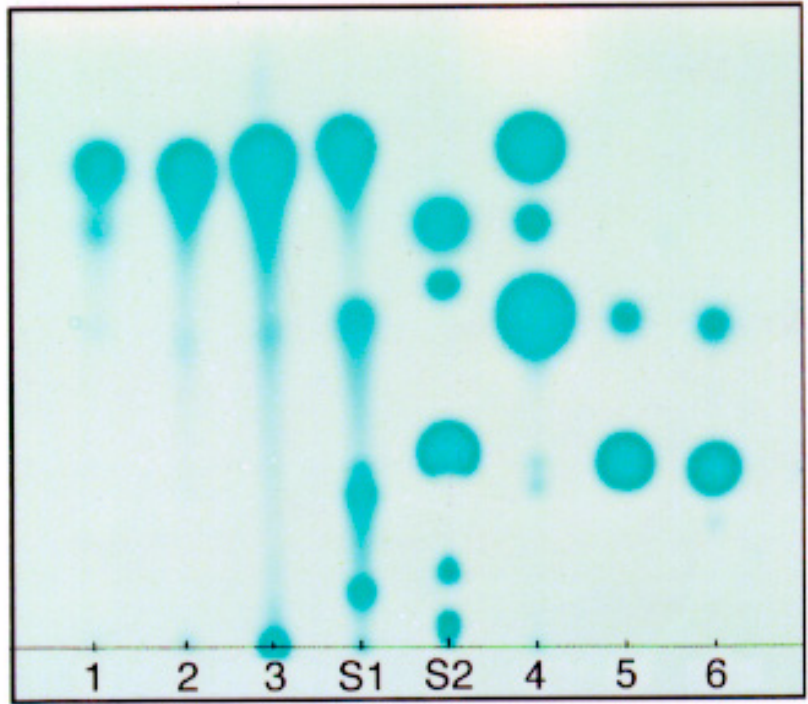

C

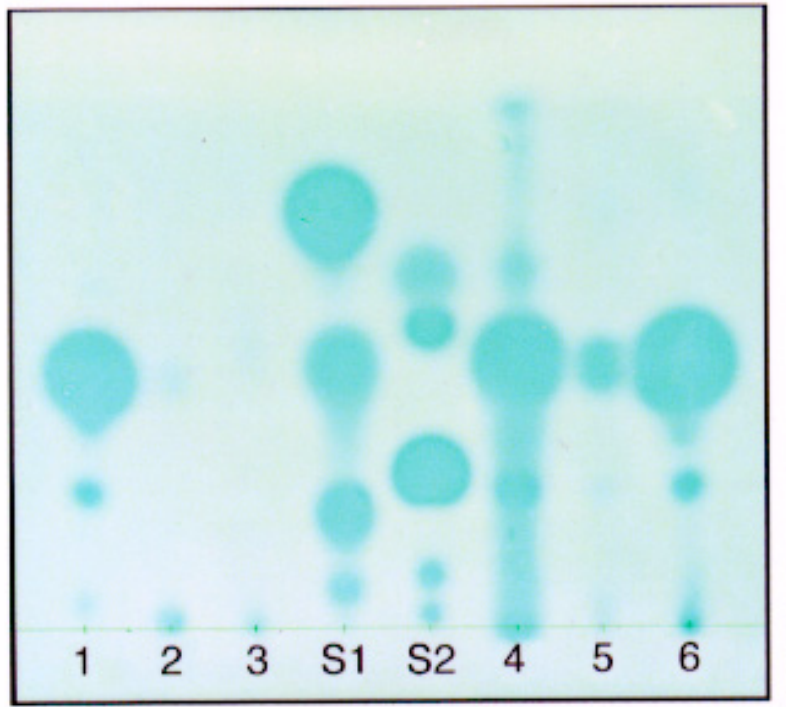

B

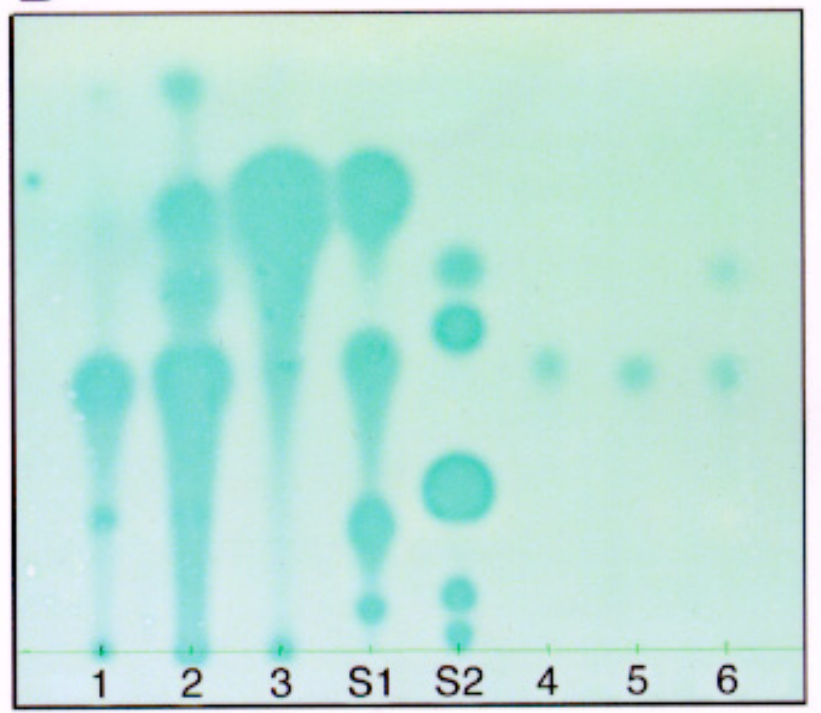

D

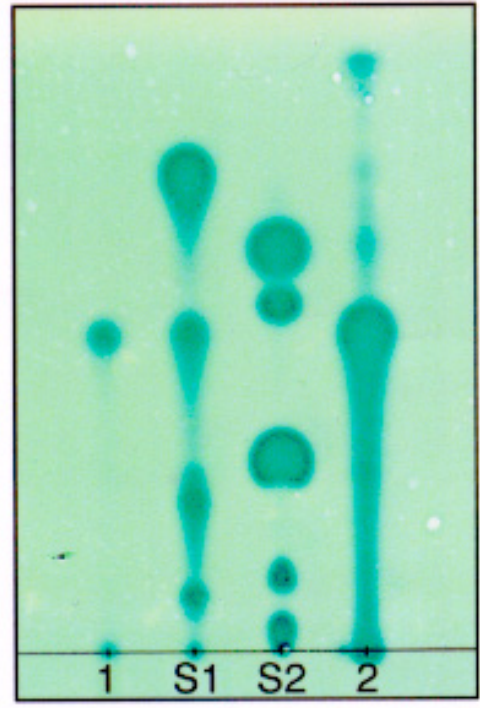

Fig. 3. Analysis of N-acylated derivatives of L-homoserine lactone (acyl-HSLs) produced by representative plant-associated bacteria. Ethyl acetate extracts were prepared from culture supernatants of a subset of isolates giving a positive reaction in the plate assays as described in the text. Samples of each extract were chromatographed on two $\mathrm{C}_{18}$ thin-layer chromatography (TLC) plates. Following development, one plate was overlaid with the traG::lacZ reporter, the other with the Chromobacterium violaceum reporter. Only the plates overlaid with the traG reporter are shown. A, Lane 1, Pseudomonas syringae pv. syringae $\mathrm{B} 728 \mathrm{a}$; lane 2 , P. syringae pv. savastanoi Olive 1670; lane 3 , P. syringae pv. coronofaciens $\mathrm{PC} 27$; lane 4 , P. fluorescens 2-79; lane 5, Ralstonia solanacearum K60; lane 6, R. solanacearum AW1. B, Lane 1, Agrobacterium tumefaciens Bo542; lane 2, Erwinia carotovora pv. atroseptica SR8; lane 3, E. carotovora pv. carotovora DM2105; lane 4, Xanthomonas campestris, pv. pelargoni X-5; lane 5, X. campestris pv. campestris 4546; lane 6, X. oryzae pv. oryzicola BLS303. C, Lane 1, Rhizobium leguminosarum bv. trifolii 162E8; lane 2, $R$. fredii USDA191; lane 3, $R$. meliloti Rm1021; lane 4, R. meliloti Rm41; lane 5, R. leguminosarum bv. trifolii 14480; lane 6, R. leguminosarum bv. phaseoli 14482. D, Lane 1, A. tumefaciens C58; lane 2, A. tumefaciens NT1(pTiC58_accR). S1 and S2 are the 3-oxo-acyl HSL and alkanoyl HSL standards as described in Figure 2. 
L-HSL in the extracts from each of these three bacteria (data not shown).

Of the three xanthomonads examined, all produced a weakly detectable activity that chromatographed with the characteristics of $\mathrm{N}$-(3-oxo-octanoyl)-L-HSL (Fig. 3B, lanes 4-6). One isolate, X. oryzae pv. oryzicola BLS303, produced, in addition, a compound that co-chromatographed with the unknown contaminant in our alkanoyl-HSL standard mix (Fig. 3B, lane 6). The $C$. violaceum reporter did not detect any active compounds in extracts from these strains (data not shown).

Among the agrobacteria tested, most produced barely detectable amounts of a single active compound that chromatographed with the properties of $\mathrm{N}$-(3-oxo-octanoyl)-L-HSL (for example, see Figure 3D, lane 1). However, strain Bo542 produced easily detectable amounts of this signal and weakly detectable amounts of a species chromatographing with the characteristics of $N$-(3-oxo-decanoyl)-L-HSL (Fig. 3B, lane 1). No other activities were detected with the $C$. violaceum reporter (data not shown).

Unlike the agrobacteria, among the Rhizobium isolates tested we observed considerable diversity. Some, such as $R$. meliloti $\mathrm{Rm} 1021$, produced only a single, highly nonpolar activity (Fig. 3C, lane 3). Rhizobium fredii 191 produced barely detectable amounts of a species that co-chromatographed with $\mathrm{N}$-(3-oxo-octanoyl)-L-HSL (Fig. 3C, lane 2) in addition to the strongly nonpolar compound. $R$. leguminosarum bv. trifolii 14480 produced a similar complement, but the $N$-(3-oxooctanoyl)-L-HSL component was present in easily detectable amounts (Fig. 3C, lane 5). Other rhizobia produced several active compounds at easily detectable levels. For example, $R$. leguminosarum bv. trifolii 162E8 (Fig. 3C, lane 1) and $R$. leguminosarum bv. phaseoli 14482 (Fig. 3C, lane 6) each produced four detectable compounds. The most active of these chromatographed with the characteristics of $\mathrm{N}$-(3-hydroxyoctanoyl)-L-HSL. In addition, each produced an active species that chromatographed with the properties of $N$-octanoyl-LHSL. The two strains also produced a strongly nonpolar activity indistinguishable from that seen in extracts of $R$. fredii 191. R. leguminosarum bv. trifolii 162E8, but not R. leguminosarum bv. phaseoli 14482, also produced an activity, easily detectable by the $C$. violaceum reporter, that chromatographed with the characteristics of $N$-hexanoyl-L-HSL (data not shown). $R$. meliloti $\mathrm{Rm} 41$ produced a minimum of seven detectable active compounds (Fig. 3C, lane 4). The two most active species chromatographed with characteristics indistinguishable from $\mathrm{N}$-(3-oxo-octanoyl)-L-HSL and $\mathrm{N}$-octanoyl-LHSL. The strain also produced a highly nonpolar species that barely moved from the origin, as well as two strongly polar activities that migrated faster than any of our standards. Finally, like E. carotovora SR8, the strain produced an activity that co-chromatographed with the contaminant present in our alkanoyl-HSL standard mix. Despite this complexity, extracts from this strain did not contain compounds detectable by the C. violaceum indicator (data not shown).

We also tested extracts from culture supernatants of a number of isolates that failed to give a positive reaction in the petri dish test. None of these strains produced compounds detectable on the TLC plates by either of the bioreporters (Table 1).

The IncRh1 Ti plasmids pTiC58 and pTiR10 confer production of $\mathrm{N}$-(3-oxo-octanoyl)-L-HSL, the Agrobacterium autoinducer (Zhang et al. 1993; Hwang et al. 1994; Fuqua and Winans 1994). However, production of this signal, synthesis of which is coded for by the traI gene (Hwang et al. 1994; Fuqua and Winans 1994; Moré et al. 1996), is repressed in the absence of the conjugal opine (Piper et al. 1993; Hwang et al. 1994; Fuqua and Winans 1994). We examined the complement of acyl-HSL signals produced by wild-type strain C58 and by the transfer-constitutive mutant, NT1(pTiC58 $\Delta a c c R$ ). This latter strain constitutively expresses traI (Zhang et al. 1993; Hwang et al. 1994). Strain C58 produced only weakly detectable levels of $\mathrm{N}$-(3-oxo-octanoyl)-L-HSL (Fig. 3D, lane $1)$, while the transfer-constitutive mutant produced this signal molecule in greatly elevated amounts (Fig. 3D, lane 2). Moreover, extracts from the transfer-constitutive mutant contained a minimum of six additional species, some chromatographing with characteristics unlike any of our standards. In fact, the pattern of activities produced by NT1(pTiC58 $\Delta a c c R$ ) resembles that produced by $R$. meliloti Rm41 (compare Figure $3 \mathrm{C}$, lane 4, with Figure 3D, lane 2).

\section{DISCUSSION}

Our surveys with the petri dish assay indicate that production of compounds with acyl-HSL signaling activity is relatively common among gram-negative bacteria that interact with plants. One or more isolates from all seven genera surveyed produced such compounds (Table 1). Among the agrobacteria, pantoea, and rhizobia tested virtually all produced active signals, while about half of the erwinias and pseudomonads tested gave a positive reaction (Table 1). Production of detectable levels of acyl-HSLs was rarer among the xanthomonads tested. However, some isolates that tested positive in the petri dish assay clearly produce active compounds detectable by TLC (Fig. 3B, lanes 4-6). With the exception of the agrobacteria and rhizobia, production of a detectable acylHSL signal largely was species- or biovar-specific. Thus, most isolates of E. carotovora and P. stewartii produced detectable levels of these signals. Similarly, all three isolates of $P$. syringae pv. tabaci tested produced detectable acyl-HSLs. However, we noted considerable diversity within some species and pathovars. For example, only a subset of the E. chrysanthemi and $P$. syringae pv. savastanoi isolates tested produced active compounds. And, although the number of isolates examined is small, certain species and pathovars, most notably E. amylovora and $P$. syringae pvs. tomato and phaseolicola, characteristically did not produce detectable acyl-HSL signals.

Such failures to detect activity must be viewed with caution. First, the organisms may contain acyl-HSL-mediated signaling systems but produce their messenger compounds at levels below that detectable by the reporter. For example, the agrobacteria that have been examined in detail all superregulate their quorum-sensing systems and produce their cognate acyl-HSL signals at very low levels when grown in standard laboratory medium (Hwang et al. 1994; Fuqua and Winans 1994). Alternatively, the organisms may produce signals, even in large amounts, that are not detectable by the reporter used in the assay. Use of several reporters with complementary specificities may minimize this problem. In this regard we have retested most of the isolates that failed to elicit a response with the traG::lacZ reporter against the lux and $C$. violaceum indicator strains. None produced signals that acti- 
vated expression of either of these alternative reporters (data not shown).

In many instances, of those that produce detectable acylHSLs, all isolates of a given taxonomic group produce the same signal or set of signals. For example, as assessed by TLC, all acyl-HSL-positive isolates of Erwinia spp. as well as the various pathovars of $P$. syringae examined produced an activity that is chromatographically indistinguishable from $\mathrm{N}$ (3-oxo-hexanoyl)-L-HSL as their major detectable signal molecule. Similarly, all isolates of Agrobacterium spp. produced $N$-(3-oxo-octanoyl)-L-HSL (Fig. 3). However, some but not all erwinia and a few $P$. syringae isolates produced additional active species. These additional signals may represent multiple quorum-sensing systems. A growing number of organisms, including V. fischeri (Kuo et al. 1994), P. aeruginosa (Pearson et al. 1994; Winson et al. 1995), and R. etli (Rosemeyer et al. 1998), express several, sometimes interrelated, quorum-sensing systems. Alternatively, they may be the products of a single acyl-HSL synthase; a number of these enzymes, including VsmI, LuxI, and RaiI, can produce several acyl-HSL derivatives (Kuo et al. 1994; Winson et al. 1995; Rosemeyer et al. 1998). Moreover, while TraI, the AI synthase of A. tumefaciens Ti plasmids, confers production of $\mathrm{N}$-(3oxo-octanoyl)-L-HSL as its major product, when expressed at high levels, this synthase produces additional acyl-HSLs at levels now detectable by the reporter strain (Fig. 3D).

Members of some taxa, best exemplified by the rhizobia, showed considerable diversity with respect to the number and nature of acyl-HSL signals produced. Some isolates, such as $R$. fredii 191, produced only a single detectable compound while others, such as $R$. meliloti $\mathrm{Rm} 41$, produced a minimum of seven detectable species. The pattern produced by this latter isolate is reminiscent of that produced by $R$. etli CNPAF512 (Rosemeyer et al. 1998). Intriguingly, R. leguminosarum bv. phaseoli 14482 apparently produces a subset of the signals produced by $R$. meliloti Rm41 (Fig. 3C, lanes 4 and 6).

Most of the rhizobia tested produced as the dominant detectable activity a compound that chromatographs with the characteristics of $N$-(3-hydroxy-octanoyl)-L-HSL. Many of the Rhizobium isolates also produced a strongly nonpolar species that barely migrates in the 60:40 methanol-water solvent system (Fig. 3 and data not shown). Several biovars of Rhizobium produce a long-chain acyl-HSL, called RLAI, involved in regulating rhizosphere-expressed genes as well as a growthinhibitory phenotype (Gray et al. 1996; Schripsema et al. 1996). This signal molecule, identified as $N$-(3-hydroxy-7-cistetradecanoyl)-L-HSL (Gray et al. 1996; Schripsema et al. 1996) is detectable by the tra reporter in its pure form (data not shown) and also in ethyl acetate extracts of culture supernatants from $R$. leguminosarum bv. phaseoli 14482, an isolate known to produce this signal (Fig. 3C, lane 6). Compounds with indistinguishable chromatographic characteristics were detected in extracts from culture supernatants of $R$. leguminosarum bv. trifolii strains 162E8 (Fig. 3C, lane 1) and 14480 (Fig. 3C, lane 5), and R. leguminosarum bv. viciae 10004 (data not shown). Whether these correspond to RLAI remains to be determined. Intriguingly, several rhizobial isolates, including $R$. fredii USDA191, $R$. leguminosarum bv. phaseoli 14482, and $R$. meliloti Rm41, produced activities even more nonpolar than RLAI (Fig. 3C, lanes 2, 4, and 6). The nature of these compounds is not known, but Gray et al. (1996) reported that $R$. meliloti $\mathrm{Rm} 1021$ produces a signal molecule that is more nonpolar than RLAI. This could correspond to the activity, which remains at or near the base line, we detected in extracts from R. meliloti Rm41 (Fig. 3C, lane 4).

Using the tra reporter, we consistently detected two acylHSLs in culture supernatants of Ralstonia solanacearum (Fig. 3A, lanes 5 and 6; and Shaw et al. 1997). One chromatographs with the properties of $N$-octanoyl-L-HSL, while the more polar compound could be $N$-(3-hydroxy-octanoyl)-L-HSL. Flavier et al. (1997b) recently reported that, based on highperformance liquid chromatography (HPLC) elution profiles, $R$. solanacearum AW1 produces $N$-octanoyl-L-HSL and $N$ hexanoyl-L-HSL. We did not detect this latter compound on chromatograms overlaid with the $C$. violaceum reporter (data not shown). This is surprising, considering that $N$-hexanoyl-LHSL is the cognate autoinducer for the quorum-sensing system that regulates production of violacein pigment in this organism (McClean et al. 1997). We have no explanation for this discrepancy. Interestingly, B1, a second wild-type isolate of $R$. solanacearum, as well as its spontaneous nonpathogenic mutant, K60, produced a pattern of acyl-HSLs indistinguishable in type and amount from that produced by AW1 (Fig. 3A and data not shown).

Surveys for acyl-HSL signal molecules and their subsequent analysis require sensitive bioreporters. These compounds generally are produced at levels so low as to escape detection by standard chemical methods. Our comparative analysis indicates that the lacZ-based tra reporter from the nopaline-type Ti plasmid pTiC58 is superior in both specificity and sensitivity, compared with any one of the three other reporter systems tested (Fig. 2). However, the tra reporter is not without limitations; it is not particularly sensitive to the short chain alkanoyl-HSLs including $N$-hexanoyl-L-HSL and does not respond at all to $N$-butanoyl- and $N$-(3-hydroxy-butanoyl)-LHSL (Fig. 2A and data not shown). In this regard, the $C$. violaceum reporter serves as a useful complement; this strain responds with reasonable sensitivity to $N$-hexanoyl- and $N$ butanoyl-L-HSL (Fig. 2D). Thus, in our TLC analyses, we tested all of our samples with both indicators. This proved enlightening; several isolates, including all of the otherwisepositive $P$. syringae pathovars, $P$. fluorescens $2-79$, and especially $R$. leguminosarum bv. trifolii $162 \mathrm{E} 8$, produced a compound with the chromatographic characteristics of $\mathrm{N}$ hexanoyl-L-HSL that was detectable only with the $C$. violaceum reporter (data not shown). The tra reporter also detected activities with chromatographic properties unlike those of any of our standards. Some of these, for example spot 11 in the extracts from $P$. fluorescens 2-79 (Fig. 2A), could represent acyl-HSLs with atypical side chains having an odd number of carbons, branches, or one or more unsaturations. Others, such as the fast-migrating species present in extracts from cultures of E. carotovora pv. atroseptica SR8 (Fig. 3B, lane 2), R. meliloti Rm41 (Fig. 3C, lane 4), and A. tumefaciens NT1(pTiC58 $\Delta a c c R$ ) (Fig. 3D, lane 2), could represent compounds with completely novel structures. However, the strongly polar compound in extracts from the A. tumefaciens strain is dependent on TraI; we detect it only in extracts from strains overexpressing the acyl-HSL synthase.

While acyl-HSLs constitute the most well-studied family of signal molecules associated with quorum-sensing systems, other types of compounds also are used. For example, few 
xanthomonads produce detectable amounts of compounds with acyl-HSL activity. However, two isolates of X. campestris pv. campestris regulate several traits in a quorumdependent fashion. Strain B-24 uses a diffusible, nonnitrogenous substituted lactone as a signal molecule to regulate production of xanthomonadin pigments as well as production of extracellular polysaccharides (EPS; Poplawsky and Chun 1997; Chun et al. 1997). Similarly, strain 8004 regulates production of extracellular enzymes involved in pathogenicity, as well as EPS, via an uncharacterized diffusible signal molecule (Barber et al. 1997). Based on an analysis of cross-signaling, these two xanthomonads apparently produce more than one somewhat interchangeable signals in a manner analogous to the production of different forms of acyl-HSLs (Poplawsky et al. 1998). These signals are not detectable by the traG::lacZ reporter (Poplawsky and Chun 1997; Barber et al. 1997). Organisms also may express more than one quorum-sensing system, each responding to a different class of signal molecules. For example, $R$. solanacearum utilizes a volatile fatty acid, 3-hydroxy palmitic acid methyl-ester (3-OH-PAME) to regulate traits involved in pathogenicity in a densitydependent manner (Clough et al. 1997; Flavier et al. 1997a). As described above, this organism also produces a minimum of two acyl-HSLs (Fig. 3A, lanes 5 and 6; Flavier et al. $1997 b)$. The gene systems in $R$. solanacearum regulated by the acyl-HSLs remain unknown. However, work from Denny's group indicates that production of the acyl-HSL signals is controlled by the regulatory system responsive to 3-OH PAME (Flavier et al. 1997b).

Although many of the tested organisms produce quorumsensing signal molecules, the traits controlled by this regulatory system are known only for a few. Thus, A. tumefaciens regulates conjugal transfer of the Ti plasmids by quorum-sensing (Piper et al. 1993; Fuqua and Winans 1994), while E. carotovora regulates production and secretion of extracellular enzymes associated with pathogenicity (Jones et al. 1993; Pirhonen et al. 1993). Similarly, P. stewartii regulates another pathogenicity determinant, production of capsular polysaccharide by acyl-HSLmediated autoinduction (Beck von Bodman and Farrand 1995). On the other hand, $P$. syringae pv. tabaci, although producing a quorum-sensing signal, does not use this signal to regulate expression of genes overtly required for pathogenesis (Y.-C. Chen, unpublished observations). Among the saprophytes, $P$. fluorescens 2-79 most probably regulates production of phenazine antibiotics by a quorum-sensing mechanism (Mavrodi et al. 1998) in a manner similar to that of $P$. aureofaciens 30-84 (Pierson et al. 1994). However, $P$. fluorescens 1855.344 , which does not produce phenazines or other known antibiotics, also does not produce detectable amounts of an acyl-HSL signal. Thus, this regulatory strategy is used by these plant-associated bacteria to control a broad range of specialty traits. The challenge for the future will be to determine what traits are regulated by quorum-sensing in these organisms, as well as the roles of these traits in the biology of these bacteria, especially as they interact with their plant hosts.

\section{MATERIALS AND METHODS}

\section{Bacterial strains and plasmids.}

Agrobacterium tumefaciens NT1 is C58 cured of its Ti plasmid (Watson et al. 1975). The strain is prototrophic and susceptible to most commonly used antibiotics. Chromobacterium violaceum $\mathrm{CV} 026 \mathrm{blu}$ is a derivative of the autoinducer reporter strain CV026 (McClean et al. 1997), and was obtained from Simon Swift. Plasmid pZLR4 contains traR and a

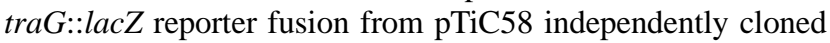
into the broad-host-range vector pBBR1MCS5 (Kovach et al. 1995). This construct codes for resistance to ampicillin/carbenicillin and gentamicin. Plasmid pWH141, harbored by Escherichia coli XL1-Blue, contains luxR and a luxI::lacZ reporter fusion from Vibrio fischeri MJ1 cloned in pSUP102 (Dunlap and Kuo 1992) while pKDT17, present in E. coli MG4, contains lasR and a lasB::lacZ reporter fusion from Pseudomonas aeruginosa PAO1 cloned into pUCP18 (Pearson et al. 1994).

\section{Media and growth conditions.}

Reporter strains were maintained on nutrient agar (Difco, Detroit, MI) or L agar (Sambrook et al. 1989) plates supplemented with the appropriate antibiotics. Antibiotics were used at the following concentrations when necessary. A. tumefaciens: carbenicillin, $100 \mu \mathrm{g} / \mathrm{ml}$; gentamicin, $30 \mu \mathrm{g} / \mathrm{ml}$. E. coli: ampicillin, $60 \mu \mathrm{g} / \mathrm{ml}$. Cultures to be assayed for production of compounds with acyl-HSL activity were grown in the following: $\mathrm{AB}$ minimal medium supplemented with $0.2 \%$ mannitol (ABM; Chilton et al. 1974) and $2 \mu \mathrm{g}$ of biotin per $\mathrm{ml}$ (ABMB) when necessary; King's B (KB) medium (King et al. 1954); Vogel-Bonner (VB) medium (Vogel and Bonner 1956); yeast extract mannitol (YEM) medium (Somasegaran and Hoben 1985); or CPG medium (Shaw et al. 1997), as noted in Table 1. Cultures of E. coli were grown at $37^{\circ} \mathrm{C}$. Cultures of all other organisms were grown at $28^{\circ} \mathrm{C}$. Liquid cultures were grown with shaking to ensure aeration.

\section{Chemicals.}

Authentic alkanoyl- and $\mathrm{N}$-3-oxo-acyl-homoserine lactones were synthesized as previously described (Shaw et al. 1997) or were the gifts of David Lynn (University of Chicago) or Anatol Eberhard (Ithaca College). The Rhizobium autoinducer, RLAI [ $N$-(3-hydroxy-7-cis-tetradecanoyl)-L-HSL] was the generous gift of E. P. Greenberg (University of Iowa). A mix of 3-hydroxy acyl-HSLs was prepared from a culture supernatant of Pseudomonas fluorescens 2-79 (Shaw et al. 1997). Samples and standards were stored at $-20^{\circ} \mathrm{C}$ in HPLC-grade ethyl acetate.

\section{Autoinducer bioassays.}

Petri dish assays were performed as follows. A 3-ml volume of sterile $0.7 \%$ agar in distilled water was cooled to $45^{\circ} \mathrm{C}$ and inoculated with about $0.5 \mathrm{ml}$ of a culture of the A. tumefaciens indicator strain grown overnight in ABM supplemented with carbenicillin. The suspension was mixed and layered over the surface of a petri dish (100 mm in diameter) containing $25 \mathrm{ml}$ of ABM agar medium supplemented with $40 \mu \mathrm{g}$ of 5-bromo-3indolyl- $\beta$-D-galactopyranoside (X-Gal) per ml. Generally, antibiotics were included in the media for overnight cultures, but not in the medium used for the overlays. The overlays were allowed to solidify, and colonies of organisms to be tested were inoculated as small patches onto the surface of the medium. When the organism to be tested did not grow on ABM, the isolate was grown to late exponential or early stationary phase in the appropriate medium (Table 1), the cells were re- 
moved by centrifugation, and a 5- $\mu \mathrm{l}$ volume of the supernatant was spotted onto the surface of the soft agar overlay. The plates were incubated for 1 to 2 days at $28^{\circ} \mathrm{C}$.

TLC analysis was performed as described by Shaw et al. (1997). Strains to be tested were grown to late exponential or early stationary phase in 5-ml volumes of the appropriate liquid medium (Table 1). Cells were removed by centrifugation and the culture fluid was extracted twice with equal volumes of ethyl acetate. The organic phases were pooled, water was removed by addition of anhydrous $\mathrm{Na}_{2} \mathrm{SO}_{4}$, and the organic phases were taken to dryness under a stream of dry argon or nitrogen gas. Residues were redissolved in 50- $\mu$ l volumes of ethyl acetate and stored at $-20^{\circ} \mathrm{C}$. Components in the ethylacetate extracts were separated by chromatography on $\mathrm{C}_{18}$ reversed-phase plates with a solvent system of methanol-water (60:40, vol/vol). The active acyl-HSLs were visualized by bioassay with the appropriate indicator strain. Preparations containing $0.7 \%$ agar were prepared in the medium appropriate to the indicator strain: ABM for A. tumefaciens, A medium (Sambrook et al. 1989) supplemented with glucose and $0.05 \%$ yeast extract for $E$. coli XL1-Blue, and L agar for E. coli MG4 and $C$. violaceum CV026blu. Medium used in assays involving the tra, lux, and las reporters was supplemented with $\mathrm{X}$ Gal. The developed thin-layer plates, held in a Plexiglas jig, were overlaid with the soft agar suspensions, the agar was allowed to solidify, and the plates were incubated at $28^{\circ} \mathrm{C}$ overnight, all as described previously (Shaw et al. 1997).

\section{Data preservation.}

After development, the thin-layer plates were set out at room temperature in a fume hood until the overlay had completely dried down into a thin film. The dried plates were stored in flexible plastic sleeves. Images of the plates were archived with a digital color scanner and processed with Photoshop version 3.0 for the Macintosh (Adobe Systems, Mountain View, CA).

\section{ACKNOWLEDGMENTS}

We thank Ryan M. Farrand for expert graphics assistance. This work was supported by grant number R01 GM52465 from the National Institutes of Health to S. K. F. and a grant from the University of Illinois Research Board to P. D. S. and S. K. F.

\section{LITERATURE CITED}

Barber, C. E., Tang, J. L., Feng, J. X., Pan, M. Q., Wilson, T. J. G., Slater, H., Dow, J. M., Williams, P., and Daniels, M. J. 1997. A novel regulatory system required for pathogenicity of Xanthomonas campestris is mediated by a small diffusible signal molecule. Mol. Microbiol. 24:555-566.

Beck von Bodman, S., and Farrand, S. K. 1995. Capsular polysaccharide biosynthesis and pathogenicity of Erwinia stewartii require induction by an $N$-acylhomoserine lactone autoinducer. J. Bacteriol. 177:5000-5008.

Chilton, M.-D., Currier, T. C., Farrand, S. K., Bendich, A. J., Gordon, M. P., and Nester, E. W. 1974. Agrobacterium tumefaciens and PS8 bacteriophage DNA not detected in crown gall tumor DNA. Proc. Natl. Acad. Sci. USA 71:3672-3676.

Chun, W., Cui, J., and Poplawski, A. 1997. Purification, characterization and biological role of a pheromone produced by Xanthomonas campestris pv. campestris. Physiol. Mol. Plant Pathol. 51:1-14.

Clough, S. J., Lee, K.-E., Schell, M. A., and Denny, T. P. 1997. A twocomponent system in Ralstonia (Pseudomonas) solanacearum modulates production of $p h c A$-regulated virulence factors in response to 3hydroxypalmitic acid methyl ester. J. Bacteriol. 179:3639-3648.
Dunlap, P. V., and Greenberg, E. P. 1991. Role of intercellular chemical communication in the Vibrio fischeri-monocentrid fish symbiosis. Pages 219-253 in: Microbial Cell-Cell Interactions. M. Dworkin, ed. American Society for Microbiology Press, Washington, DC.

Dunlap, P. V., and Kuo, A. 1992. Cell density-dependent modulation of the Vibrio fischeri luminescence system in the absence of autoinducer and LuxR protein. J. Bacteriol. 174:2440-2448.

Eberhard, A., Burlingame, A. L., Eberhard, C., Kenyon, G. L., Nealson, K. H., and Oppenheimer, N. J. 1981. Structural identification of autoinducer of Photobacterium fischeri luciferase. J. Biochem. 20: 2444-2449.

Eberl, L., Winson, M. K., Sternberg, C., Stewart, G. S. A. B., Christiansen, G., Chhabra, S. R., Bycroft, B., Williams, P., Molin, S., and Givskov, M. 1996. Involvement of $N$-acyl-L-homoserine lactone autoinducers in controlling the multicellular behaviour of Serratia liquefaciens. Mol. Microbiol. 20:127-136.

Farrand, S. K., Hwang, I., and Cook, D. M. 1996. The tra region of the nopaline-type $\mathrm{Ti}$ plasmid is a chimera with elements related to the transfer systems of RSF1010, RP4 and F. J. Bacteriol. 178:4233-4247

Flavier, A. B., Clough, S. J., Schell, M. A., and Denny, T. P. 1997a. Identification of 3-hydroxypalmitic acid methyl ester as a novel autoregulator controlling virulence in Ralstonia solanacearum. Mol. Microbiol. 26:251-259.

Flavier, A. B., Ganova-Raeva, L. M., Schell, M. A., and Denny, T. P. 1997b. Hierarchical autoinduction in Ralstonia solanacearum: Control of acyl-homoserine lactone production by a novel autoregulatory system responsive to 3-hydroxypalmitic acid methyl ester. J. Bacteriol. 179:7089-7097.

Forrai, T., Vincze, É., Bánfalvi, Z., Kiss, G. B., Randhawa, G. S., and Kondorosi, Á. 1983. Localization of symbiotic mutations in Rhizobium meliloti. J. Bacteriol. 153:635-643.

Fuqua, C., and Winans, S. C. 1994. A LuxR-LuxI type regulatory system activates Agrobacterium Ti plasmid conjugal transfer in the presence of plant tumor metabolites. J. Bacteriol. 176:2796-2806.

Fuqua, W. C., Winans, S. C., and Greenberg, E. P. 1994. Quorum sensing in bacteria: The LuxR-LuxI family of cell density-responsive transcriptional regulators. J. Bacteriol. 176:269-275.

Fuqua, W. C., Winans, S. C., and Greenberg, E. P. 1996. Census and consensus in bacterial ecosystems: The LuxR-LuxI family of quorumsensing transcriptional regulators. Annu. Rev. Microbiol. 50:727-751.

Gray, K. M., Pearson, J. P., Downie, J. A., Boboye, B. E. A., and Greenberg, E. P. 1996. Cell-to-cell signaling in the symbiotic nitrogenfixing bacterium Rhizobium leguminosarum: Autoinduction of a stationary phase and rhizosphere-expressed genes. J. Bacteriol. 178:372376.

Hwang, I., Li, P.-L., Zhang, L. H., Piper, K. R., Cook, D. M., Tate, M. E., and Farrand, S. K. 1994. TraI, a luxI homologue, is responsible for production of conjugation factor, the Ti plasmid $N$-acylhomoserine lactone autoinducer. Proc. Natl. Acad. Sci. USA 91:4639-4643.

Jones, S., Yu, B., Bainton, N. J., Birdsall, M., Bycroft, B. W., Chhabra, S. R., Cox, A. J. R., Golby, P., Reeves, P. J., Stephens, S., Winson, M. K., Salmond, G. P. C., Stewart, G. S. A. B., and Williams, P. 1993. The lux autoinducer regulates the production of exoenzyme virulence determinants in Erwinia carotovora and Pseudomonas aeruginosa. EMBO J. 12:2477-2482.

King, E. D., Ward, M. N., and Raney, D. T. 1954. Two simple media for the demonstration of pyocyanin and fluorescein. J. Lab. Clin. Med. 44:301-307.

Kovach, M. E., Elzer, P. H., Hill, D. S., Robertson, G. T., Farris, M. A., Roop, R. M., II, and Peterson, K. M. 1995. Four new derivatives of the broad-host-range cloning vector pBBR1MCS carrying different antibiotic-resistance cassettes. Gene 166:175-176.

Kuo, A., Blough, N. V., and Dunlap, P. V. 1994. Multiple N-acyl-Lhomoserine lactone autoinducers of luminescence in the marine symbiotic bacterium Vibrio fischeri. J. Bacteriol. 176:7558-7565.

Latifi, A., Foglino, M., Tanaka, K., Williams, P., and Lazdunski, A. 1996. A hierarchical quorum-sensing cascade in Pseudomonas aeruginosa links the transcriptional activators LasR and RhlR (VsmR) to expression of stationary-phase sigma factor RpoS. Mol. Microbiol. 21:1137-1146.

Mavrodi, D. V., Ksenzenko, V. N., Bonsall, R. F., Cook, R. J., Boronin, A. M., and Thomashow, L. S. 1998. A seven-gene locus for synthesis of phenazine-1-carboxylic acid by Pseudomonas fluorescens 2-79. J. Bacteriol. 180:2541-2548. 
McClean, K. H., Winson, M. K., Fish, L., Taylor, A., Chhabra, S. R., Camara, M., Daykin, M., Lamb, J. H., Swift, S., Bycroft, B. W., Stewart, G. S. A. B., and Williams, P. 1997. Quorum-sensing and Chromobacterium violaceum: Exploitation of violacein production and inhibition for the detection of $N$-acylhomoserine lactones. Microbiology 143:3703-3711.

Moré, M. I., Finger, L. D., Stryker, J. L., Fuqua, C., Eberhard, A., and Winans, S. C. 1996. Enzymatic synthesis of a quorum-sensing autoinducer through use of defined substrates. Science 272:1655-1658.

Nealson, K. H., Platt, T., and Hastings, J. W. 1970. Cellular control of the synthesis and activity of the bacterial luminescent system. J. Bacteriol. 104:313-322.

Ochsner, U. A., and Reiser, J. 1995. Autoinducer-mediated regulation of rhamnolipid biosurfactant synthesis in Pseudomonas aeruginosa. Proc. Natl. Acad. Sci. USA 92:6424-6428.

Passador, L., Cook, J. M., Gambello, M. J., Rust, L., and Iglewski, B. H. 1993. Expression of Pseudomonas aeruginosa virulence genes requires cell-to-cell communication. Science 260:1127-1130.

Pearson, J. P., Gray, K. M., Passador, L., Tucker, K. D., Eberhard, A., Iglewski, B. H., and Greenberg, E. P. 1994. Structure of the autoinducer required for expression of Pseudomonas aeruginosa virulence genes. Proc. Natl. Acad. Sci. USA 91:197-201.

Pearson, J. P., Pesci, E. C., and Iglewski, B. H. 1997. Roles of Pseudomonas aeruginosa las and rhl quorum-sensing systems in control of elastase and rhamnolipid biosynthesis genes. J. Bacteriol. 179:57565767.

Pierson, L. S., III, Keppenne, V. D., and Wood, D. W. 1994. Phenazine antibiotic biosynthesis in Pseudomonas aureofaciens 30-84 is regulated by PhzR in response to cell density. J. Bacteriol. 176:3966-3974.

Piper, K. R., Beck von Bodman, S., and Farrand, S. K. 1993. Conjugation factor of Agrobacterium tumefaciens regulates Ti plasmid transfer by autoinduction. Nature 362:448-450.

Pirhonen, M., Flego, D., Heikinheimo, R., and Palva, E. T. 1993. A small diffusible signal molecule is responsible for the global control of virulence and exoenzyme production in the plant pathogen Erwinia carotovora. EMBO J. 12:2467-2476.

Poplawsky, A. R., and Chun, W. 1997. pigB determines a diffusible factor needed for extracellular polysaccharide slime and xanthomonadin production in Xanthomonas campestris pv. campestris. J. Bacteriol. 179:439-444.

Poplawsky, A. R., Chun, W., Slater, H., Daniels, M. J., and Dow, J. M. 1998. Synthesis of extracellular polysaccharide, extracellular enzymes, and xanthomonadin in Xanthomonas campestris: Evidence for the involvement of two intercellular regulatory signals. Mol. PlantMicrobe Interact. 11:68-70

Puskas, A., Greenberg, E. P., Kaplan, S., and Schaefer, A. L. 1997. A quorum-sensing system in the free-living photosynthetic bacterium Rhodobacter sphaeroides. J. Bacteriol. 179:7530-7537.
Rosemeyer, V., Michiels, J., Verreth, C., and Vanderleyden, J. 1998. luxI and luxR-homologous genes of Rhizobium etli CNPAF512 contribute to synthesis of autoinducer molecules and nodulation of Phaseolus vulgaris. J. Bacteriol. 180:815-821.

Sambrook, J., Fritsch, E. F., and Maniatis, T. A. 1989. Molecular Cloning: A Laboratory Manual. 2nd ed. Cold Spring Harbor Laboratory, Cold Spring Harbor, NY.

Schripsema, J., de Rudder, K. E. E., van Vliet, T. B., Lankhorst, P. P., de Vroom, E., Kijne, J. W., and van Brussel, A. A. N. 1996. Bacteriocin small of Rhizobium leguminosarum belongs to the class of $\mathrm{N}$-acyl-Lhomoserine lactone molecules, known as autoinducers and as quorum-sensing co-transcription factors. J. Bacteriol. 178:366-371.

Shaw, P. D., Gao, P., Daly, S. L., Cha, C., Cronan, J., Jr., Rinehart, K. L., and Farrand, S. K. 1997. Detecting and characterizing $N$-acylhomoserine lactone signal molecules by thin-layer chromatography. Proc. Natl. Acad. Sci. USA 94:6036-6041.

Somasegaran, P., and Hoben, H. J. 1985. Page 273 in: Methods in Legume-Rhizobium Technology. NiftTAL, University of Hawaii Press, Honolulu.

Swift, S., Karlyshev, A. V., Fish, L., Durant, E. L., Winson, M. K., Chhabra, S. R., Williams, P., Macintyre, S., and Stewart, G. S. A. B. 1997. Quorum sensing in Aeromonas hydrophila and Aeromonas salmonicida: identification of the LuxRI homologs AhyRI and AsaRI and their cognate $\mathrm{N}$-acylhomoserine lactone signal molecules. J. Bacteriol. 179:5271-5281.

Thomashow, L. S., and Weller, D. M. 1988. Role of a phenazine antibiotic from Pseudomonas fluorescens in biological control of Gaeumannomyces graminis var. tritici. J. Bacteriol. 170:3499-3508.

Throup, J. P., Camara, M., Briggs, G. S., Winson, M. K., Chhabra, S. R., Bycroft, B. W., Williams, P., and Stewart, G. A. S. B. 1995. Characterization of the yenI/yenR locus from Yersinia entercolitica mediating the synthesis of two $N$-acylhomoserine lactone signal molecules. Mol. Microbiol. 17:345-356.

Vogel, H. J., and Bonner, D. M.. 1956. Acetyl ornithinase of Escherichia coli: Partial purification and some properties. J. Biol. Chem. 218:97106.

Watson, B, Currier, T. C., Gordon, M. P., Chilton, M.-D., and Nester, E. W. 1975. Plasmid required for virulence of Agrobacterium tumefaciens. J. Bacteriol. 123:255-264

Winson, M. K., Camara, M., Latifi, A., Foglino, M., Chhabra, S. R., Daykin, M., Bally, M., Chapon, V., Salmond, G. P. C., Bycroft, B. W., Lazdunski, A., Stewart, G. S. A. B., and Williams, P. 1995. Multiple $\mathrm{N}$-acyl-L-homoserine lactone signal molecules regulate production of virulence determinants and secondary metabolites in Pseudomonas aeruginosa. Proc. Natl. Acad. Sci. USA 92:9427-9431.

Zhang, L. H., Murphy, P. J., Kerr, A., and Tate, M. E. 1993. Agrobacterium conjugation and gene regulation by $N$-acyl-L-homoserine lactones. Nature 362:446-448.

\section{Erratum, Volume 11 no. 11, 1998}

In the paper by Chung Cha, Ping Gao, Yu-Ching Chen, Paul D. Shaw, and Stephen K. Farrand (11:1119-1129) entitled "Production of Acyl-Homoserine Lactone Quorum-Sensing Signals by Gram-Negative Plant-Associated Bacteria" the Ralstonia solanacearum strains B1 and K60 were incorrectly identified as being the wild-type pathogenic strain and a spontaneous, nonpathogenic mutant of B1, respectively. This is reversed: strain K60 is the wild-type pathogen and strain B1 is the spontaneous, nonpathogenic mutant. Appropriate corrections, in which B1 should read as K60 and K60 should read as B1, should be made to footnote 'e' of Table 1, to the text of the Results section on page 1124, and to the text of the Discussion section on page 1126. Finally, lane 5 of Figure $3 \mathrm{~A}$ shows an extract of a culture supernatant from $R$. solanacearum $\mathrm{B} 1$, the mutant, rather than from K60 as noted in the caption. This error does not affect any of the conclusions regarding production of acyl-HSL signal molecules by these strains of $R$. solanacearum. 